\title{
Protocol for a Cluster Randomized Trial To Evaluate The Effectiveness of Intervention On Myopia (The ES-SCI Study Intervention Section)
}

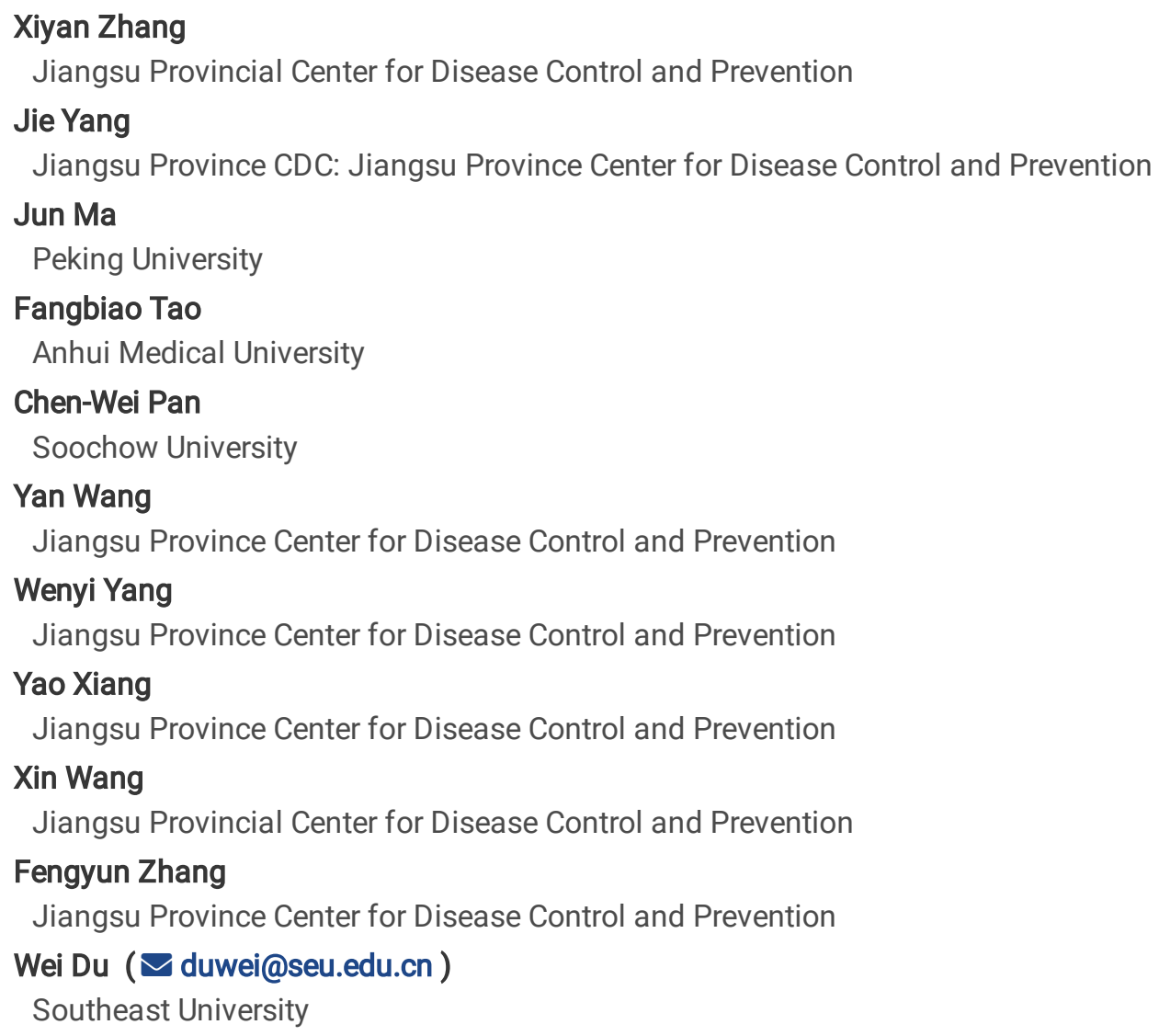

\section{Research Article}

Keywords: design, baseline, student, surveillance, cohort, intervention

Posted Date: October 25th, 2021

DOI: https://doi.org/10.21203/rs.3.rs-898485/v1

License: (c) (i) This work is licensed under a Creative Commons Attribution 4.0 International License. Read Full License 


\section{Abstract}

Background: Myopia is commonly observed among Chinese students aged 6-18 years.

Objectives: To describe the protocol of the cluster-randomized trial to determine and evaluate the effectiveness and economic burden of multi-technology route intervention on myopia among eastern Chinese students.

Methods凹A cluster-randomized trial will be conducted to test the effectiveness of an intervention to prevent the progression or onset of myopia. The effectiveness evaluation will be tested in comparison with the control group. The participating students will be assessed at baseline and 3-,6-.9-.12-,24-,36-,48-,60-months follow up.

Discussions: Eastern Chinses Student common disease Surveillance Cohort and Intervention study is designed to provide accurate epidemiological clues and precise prevention strategies for school-age students. This study is a large sample and long-term followup cluster randomized controlled trial in eastern China. The intervention population is students aged 7.5-9.5. This study aims to provide an evidence-based basis for the intervention of myopia among Chinese students and provide the theoretical basis for the effect evaluation.

Trial registration: ChiCTR2100051064. Registered on 11 Sep 2021.

\section{Article Summary}

- A large scale, long-term follow-up cluster randomized controlled trial concerning myopia in eastern China.

- The intervention was adapted from Eastern Chinses Student common disease Surveillance Cohort and Intervention (ES-SCI) study --intervention section.

- Providing a basis for establishing the theoretical model of myopia control.

- Exploring optimal ways to reduce myopia will potentially be rolled out across the nation.

\section{Background}

Alongside rapid economic and social development in China, the disease burden in Chinese students has undergone noticeable changes, with primary contributors shifting from infectious diseases to non-communicable diseases (NCDs)[1-3]. Of major NCDs, myopia, obesity, and elevated blood pressure are abnormal conditions commonly seen in Chinese children and adolescents. From Jiangsu province of Eastern China, one of the most developed regions, we have carried out school-based surveillance of commonly seen diseases in children and adolescents since 2017. Over the last three years, the prevalence of obesity, myopia and elevated blood pressure of students all demonstrated trends upward and maintained a relatively high level [4-6]

Environmental factors have a significant impact on these commonly seen diseases in children and adolescents, with behavioral factors playing a more substantial role than genetic factors [7-9]. Interventions on modifying specific environmental factors included moderate exercise, keeping a healthy lifestyle, upgrading the visual environment, etc. [10-12]. A recent trial in northwestern China reported that over one year, the mean uncorrected visual acuity (UCVA) from the intervention student group with two additional 20-min outdoor activities was significantly better than their control counterparts [13]. The systematic review also demonstrated that environmental and behavioral interventions could result in weight loss in an obese child population [14]. This protocol mainly focuses on the environmental and behavioral intervention research of myopia in students' common diseases.

The onset and development of myopia is an irreversible process [15]. Based on this principle, the intervention group can be divided into two groups: 1. For the myopia students, the intervention of myopia is to delay the progress of myopia. 2. For the non-myopia population, primary prevention should be carried out to prevent the onset of myopia. Therefore, it is necessary to develop precise intervention strategies for different groups of children. Jinhai Huang's[16] research team recently summarized 16 myopia intervention methods by using network meta-analysis. It pointed out that in the summarized 30 randomized controlled trials, atropine, pirenzepine, corneal plastic glasses, and peripheral defocus glasses can control myopia progression compared with single vision spectacle lenses (SVSLS) or placebo (PBO) group. Kovin S. Naidoo's [17] team assessed the economic burden associated with potential global myopia, which indicates that East Asia will bear the highest economic loss due to myopia in the future. Xun 
$\mathrm{Xu}[18]$ simulated and predicted the trend of myopia prevalence in the next ten years in China from 6 to 18 years old without intervention effect. This study simulated the prediction results under $10 \%, 30 \%, 50 \%$ and $90 \%$ intervention effect. However, these studies also had some limitations: 1 . There is considerable heterogeneity in the study, which could not guarantee all the research objects; 2 . The evidence of intervention for a non-myopic population is insufficient, and the outcome evaluation index is not unified.

Therefore, it is necessary to carry out a multi-centre, unified study object and outcome variable, long-term follow-up of the whole group of cluster randomized controlled study. Meanwhile, the direct and indirect variables related to cost and benefit were collected based on a randomized control study. The group strategies of myopia intervention were evaluated in economics (cost-effective analysis), which provided the theoretical basis for the national myopia prevention and control policy.

\section{Objective}

This is a school-based cluster randomized controlled trial (RCT)with the primary aim to evaluate the effectiveness and economic burden of a multi-technology route intervention on myopia among students aged 7.5 to 9.5 years.

Pilot study. Small sample size was selected and divided into intervention group and control group. These students are followed up for three months to observe the initial effect of the intervention.

\section{Hypothesis}

Students in the intervention group will have different disease propensity, incidence, and progression compared to those in the control group. Therefore, the intervention group include myopia and non-myopia students.

\section{Methods/design}

\section{Study design}

This cluster RCT will be carried out in 6 schools from 3 municipalities, each of which represents a distinctive level of socioeconomic development geographically clustered in Jiangsu Province, i.e., Peicounty a rapid-developing city located in the north, Yizheng a steady-developing city in the middle, Changshu an advanced-developing city in the south. Before the RCT study, sufficient observational (Surveillance) and analytical (Cohort) studies were carried out. We concluded that education pressure and time outdoors are still at play in the formation of myopia[6,19,20]. The intervention program mainly focuses on the improvement of the environment and behaviour of students. (Fig.1) Baseline data collection will start at the second year of the cohort study (ES-SCl study cohort section). All participating students will be assessed annually on visual indices (such as refractive error, axial length) and followed up for a total of 5 years. During the first year follow-up visit, additional assessments will occur at 3-, 6-, 9-months after the baseline.

\section{Patient and Public Involvement}

The project was developed Eastern Chinses Student common disease Surveillance Cohort and Intervention (ES-SCI) study. Patient and public (children and their parent) involvement representatives were supported by annually basic public health of child and adolescent health (myopia intervention) funding. Relevant schools, CDC and Community hospitals ensured public involvement at all stages. They collaborated on intervention design, recruitment and consent processes, accessibility of information leaflets, data collection, interpretation and dissemination. Parent and their child would receive physical examination feedback every year. In addition, children involved in myopia prevention and control are not patients.

\section{Eligibility criteria}

Inclusion criteria for students to receive targeted environmental or behaviour interventions: (1) No severe other eye diseases;(2) Chinese Han ethnicity;(3) Ability of parents/guardians to provide informed consent;(4) Aged between 7.5 to 9.5 years. Inclusion criteria for students to Low-Intensity Laser Therapy for Slowing the progression of Myopia added an additional rule is: myopia ranges from $-1.50 \mathrm{D}$ to $-5.00 \mathrm{D}$. 
Exclusion criteria: (1) There are serious eye diseases, including nystagmus, glaucoma, cataract, photosensitivity, retinal detachment, etc. (2) The age of students is not $7.5 \sim 9.5$ years old. (3) Parents or guardians did not provide informed consent.

\section{Sample size calculation}

The specific parameters are as follows: $a=0.01, P_{C}=38.1 \%, P_{E}$ (intervention group) $=16.2 \%, Z_{a}=2.576 \otimes Z_{\beta}=2.326$, design effect $=$ 1.2 , drop-out rate $=5 \%$, the calculated intervention and control sample size were respectively, intervention(1-4) group $=120$, control group $=120 \bigotimes$ total sample size $=960$.

\section{The intervention group and control group}

Targeted environmental or behaviour intervention methods of this cluster randomized controlled trial are as follows: the intervention population was divided into four groups. Each intervention group was matched with a control group.

Intervention method 1: This population in the intervention group and the control group simultaneously implemented recess activities, and the intervention increased an additional 40 minutes of outdoor activities. On holidays the intervention group is also to ensure 40 minutes of outdoor activities for the intervention group. The intervention is called locked the door to increase the time for outdoor activities.

Intervention method 2: The intervention group was arranged in the school where the government transformed lighting and desks and chairs, while the control group is set in another entire school. This research design is closer to the actual world study. The intervention is called Indoor lighting of light source equipment transformation, desks and chairs adjustment.

Intervention method 3: Study concerning low-Intensity laser therapy for slowing the progression of myopia has been ongoing [12]. There is no sufficient evidence to prove the long-term effect of the intervention, so we will combine the cohort design to observe the long-term effect of the intervention population for at least five years. The control group came from another school. The intervention is called Low-Intensity Laser Therapy for Slowing the progression of Myopia.

Intervention method 4: Students' near sight habits are considered to be essential factors affecting myopia [6, 21]. The intervention program is to use wearable environment monitoring equipment to warn of lousy eye habits to students. The control group come from another school.

\section{Randomization, allocation and confidentially}

A total of 6 primary schools have been randomly selected into the ES-SCl cohort study from the school directory in the provincial Department of Education to minimize contamination which may occur if two classes of the same school receive the intervention and the other does not. All Grade Two to three students from each primary school will be considered. To avoid spill-over effects within school classes, we will conduct a cluster-randomized controlled trial using school class as a randomization unit, with four classes as an intervention group and four classes as a control group for each intervention method. We will use block randomization with computer randomly generated to guarantee the equality of sample sizes between study groups. However, due to the nature of the intervention, study participants cannot be completely blinded to the intervention.

Junior scientists supervise the baseline assessment until students have been recruited and baseline data collection has been completed. Research assistants who perform the computer-assisted follow up assessments for primary and secondary outcomes will be blinded to the group allocation. The Senior Program Coordinator will be informed under circumstances when these assistants inadvertently are un-blinded.

Students allocated to the control group are from the cohort study database matching with the intervention group in gender, age and refractive parameters. They will also be tracked (attending clinical examination) at baseline and 3-,6-.9-.12-,24-,36-,48-,60-months. Considering the nature of the intervention method 2, control participants may not be immune to its effects. Therefore, during the same study period, control participants will be observed for the same exposure.

\section{Study variables and methods of assessment}


The effectiveness measures are physical, biological, and economical from baseline and after 3,6,9,12,24,36,48 and 60 months. (Table1)

\section{Primary outcomes:}

Refractive error. Pupils participated in an ophthalmic examination with an auto-refractor applied with cycloplegia. The cycloplegic refraction is measured using tropicamide phenylephrine eye drops every $5 \mathrm{~min}$, three times. Then refractive error is measured $30 \mathrm{~min}$ after the first drop of tropicamide by auto-refractor with five repeated measurements.

Uncorrected visual acuity. is defined as visual acuity measured without correcting refractive errors. Best-corrected visual acuity (BCVA) is examined after correcting refractive errors.

Axial length: The Axis of the eye is described as an optical instrument. The distance from the surface layer of the eyeball receiving light, that is, from the cornea lens vitreous retina (the innermost layer of receiving light), is regarded as a central axis of the optical system in physics is called the "eye axis".

\section{Secondary outcomes:}

Biological samples: Collecting biological samples includes urine, saliva, and faeces.

Height, Weight, and Blood pressure: Anthropometric measurements were taken to obtain height, weight, and blood pressure according to standard techniques.

Overweight and obesity. was defined by the Screening for overweight and obesity among school-age children and adolescents (WST586-2018) and BMI is specified as weight in kilograms divided by height in meters squared [22].

Elevated blood pressure: was defined using the National Blood Pressure Reference for Chinese Han Children and Adolescents (CCBP) thresholds, i.e., $\geq 95$ th percentile as elevated BP [23].

Cost-effectiveness: All health system costs/ Health outcomes.

\section{Adverse events and evaluations:}

Intraocular pressure: Non-contact tonometer was used to check intraocular pressure.

Fundus examination: Direct ophthalmoscopy was used to examine the fundus. Attention should be paid to congenital fundus abnormalities, optic atrophy, retinopathy, macular disease, retinal detachment, vitreous opacity, and primary vitreous hyperplasia.

\section{Statistical analysis plan}

Descriptive statistics will present the sample characteristics, and the results will be written as mean, standard deviation and percentage. Pearson's chi-square test and Student's t-test will be used to compare categorical and continuous variables, respectively. Generalized linear mixed models analysis will be used for repeated measurements (baseline and 3-,6-.9-.12-,24-,36-,48-,60-months) $[24,25]$.

All data will be analyzed according to the intention-to-treat principle. The statistics will be carried out in office software, SAS 10.0 software and R software. A $P \otimes 0.05$ will be considered statistically significant.

\section{Ethics approval and Study status (Trial status)}

Ethics approval was obtained from the Institutional Review Board of Ethics committee of Jiangsu Province CDC. (Ethics Approval Number: JSJK2021-B008-02, JSJK2021-B010-01, JSJK2021-B011-01).

Student recruitment has begun in August 2021.

\section{Discussion}


Myopia is a common disease among Chinese students, which have a profound impact on the future of adulthood. The initial pilot study has confirmed the study feasibility without any safety concerns being reported. Student recruitment is ongoing and expected to complete by August 2021. The heterogeneity of students will be calculated using a cohort baseline database. This intervention focuses on behaviour and students' related environment, mainly including classroom lights or desks and chairs, low-intensity laser therapy[12], a continuous behaviour monitoring feedback mechanism, or outdoor activity. Social determinants of health, environmental and lifestyle factors are strongly associated with common childhood diseases[26-28].

This study is the first of its kind, a large scale, long-term follow-up cluster randomized controlled trial in eastern China, with the purpose of unprecedented evidence on the clinical and cost-effectiveness of selected intervention strategies. The trial findings will be considered to develop relevant training resources for teachers in primary school, which will be made publicly available. Recommendations about the optimal way to reduce myopia will potentially be rolled out across the nation.

\section{Abbreviations}

RCT

randomized controlled trial

\section{Declarations}

\section{Potential biases}

To minimize selection bias, the study population was selected form ES-SCl study cohort section and intervention-control groups were balanced through the baseline results. The trial statistician is advised of whether there is potential unblinding and this appears to bias the reporting or not.

\section{Study status (Trial status)}

Ethics approval was obtained from Institutional Review Board of Ethics committee of Jiangsu Province CDC. Student recruitment will begin in October 2021.

\section{Acknowledgements}

The author would like to thank Dr. Dian Lu for their constructive suggestions and help for the manuscript.

\section{Funding}

Annually basic public health of child and adolescent health (myopia intervention) funding was covered by the Jiangsu Provincial Department of Finance and Jiangsu Provincial Health Committee for 2019-2020[2019 64],2020-2021[2020 124] [2020 52],20212026 (un-issued) respectively. The role of the funder(s) is not applicable in this study.

This research was also supported by Demonstration project of comprehensive prevention and control of emerging infectious diseases (BE2015714) http://www.jshealth.com/xxgk/sewcjz/xmzl/sbjkt/201708/t20170830_59379.html.

\section{Authors' contributions}

All authors have read and approved the manuscript.Data curation: XZ, JY. Investigation: YX, XW. Methodology: YW. Project administration: FZ,WD. Design and advice: FT,JM,CP. Article modification: WD,YW. Supervision: FZ,WD. Writing the original draft: XZ, WY,FZ『WD.

\section{Availability of data and materials}

Not applicable.

\section{Consent for publication}

All authors agreed for publication. 


\section{Competing interests}

The authors declare that they have no competing interests.

\section{References}

1. Li D, Xu K, Wang X. Market failure and government regulation of public health services. Zhong Guo Wei Sheng Shi Ye Guan Li. 2003:207-13.

2. Yang G, Wang Y, Zeng Y, Gao GF, Liang X, Zhou M, et al. Rapid health transition in China, 1990-2010: findings from the Global Burden of Disease Study 2010. LANCET. 2013;381:1987-2015.

3. Wang L, Wang Z, Ma Q, Fang G, Yang J. The development and reform of public health in China from 1949 to 2019. Global Health. 2019;15:45.

4. Zhang X, Yang J, Wang Y, Liu W, Yang W, Gao L, et al. Epidemiological characteristics of elevated blood pressure among middle and high school students aged 12-17 years: a cross-sectional study in Jiangsu Province, China, 2017-2018. BMJ OPEN. 2019; 9:e27215.

5. Zhang X, Zhang F, Yang J. Prevalence of overweight and obesity among primary school-aged children in Jiangsu Province, China, 2014-2017. PLOS ONE. 2018; 13.

6. Zhang X, Wang Y, Pan C, Yang W, Xiang Y, Yang J, et al. Effect of Genetic-Environmental Interaction on Chinese Childhood Myopia. J OPHTHALMOL. 2020; 2020:6308289.

7. Reddon H, Guéant J, Meyre D. The importance of gene-environment interactions in human obesity. Clinical science (London, England: 1979). 2016; 130:1571-97.

8. Li W, Bai C, Liu H. Genetic and environmental-genetic interaction rules for the myopia based on a family exposed to risk from a myopic environment. GENE. 2017;626:305-8.

9. Waken RJ, de Las Fuentes L, Rao DC. A Review of the Genetics of Hypertension with a Focus on Gene-Environment Interactions. CURR HYPERTENS REP. 2017;19:23.

10. Tay SA, Farzavandi S, Tan D. Interventions to Reduce Myopia Progression in Children. Strabismus. 2017;25:23-32.

11. Igarashi Y, Nogami Y. The effect of regular aquatic exercise on blood pressure: A meta-analysis of randomized controlled trials. EUR J PREV CARDIOL. 2018;25:190-9.

12. Xiong F, Mao T, Liao H, Hu X, Shang L, Yu L, et al. Orthokeratology and Low-Intensity Laser Therapy for Slowing the Progression of Myopia in Children. BIOMED RES INT. 2021; 2021:8915867.

13. Jin JX, Hua WJ, Jiang X, Wu XY, Yang JW, Gao GP, et al. Effect of outdoor activity on myopia onset and progression in schoolaged children in northeast China: the Sujiatun Eye Care Study. BMC OPHTHALMOL. 2015;15:73.

14. Lv N, Azar K, Rosas LG, Wulfovich S, Xiao L, Ma J. Behavioral lifestyle interventions for moderate and severe obesity: A systematic review. PREV MED. 2017;100:180-93.

15. Wu PC, Huang HM, Yu HJ, Fang PC, Chen CT. Epidemiology of Myopia. Asia Pac J Ophthalmol (Phila). 2016;5:386-93.

16. Huang J, Wen D, Wang Q, McAlinden C, Flitcroft I, Chen H, et al. Efficacy Comparison of 16 Interventions for Myopia Control in Children: A Network Meta-analysis. OPHTHALMOLOGY. 2016;123:697-708.

17. Naidoo KS, Fricke TR, Frick KD, Jong M, Naduvilath TJ, Resnikoff S, et al. Potential Lost Productivity Resulting from the Global Burden of Myopia: Systematic Review, Meta-analysis, and Modeling. OPHTHALMOLOGY. 2019;126:338-46.

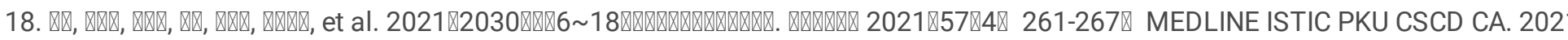

19. Zhang X, Yang W, Yang J, Du W, Xiang Y, Wang X, et al. Relationship between Family and Myopia: Based on the Jiangsu School Student Myopia Study. J OPHTHALMOL. 2021; 2021:6754013.

20. Zhang X, Zhou Y, Yang J, Wang Y, Yang W, Gao L, et al. The distribution of refraction by age and gender in a non-myopic Chinese children population aged 6-12 years. BMC OPHTHALMOL. 2020;20:439.

21. Enthoven CA, Tideman JWL, Polling JR, Tedja MS, Raat $\mathrm{H}$, Iglesias Al, et al. Interaction between lifestyle and genetic susceptibility in myopia: the Generation R study. EUR J EPIDEMIOL. 2019:1-8.

22. NHCoPRoC. Screening for overweight and obesity among school-age childre and adolescents(WST 586-2018). 2018. 
23. NHCoPRoC. Reference of screening for elevated blood pressure among children and adolescents aged $7 \sim 18$ years (WST 6102018). 2018.

24. Yan YW, Briollais L. Mixed-effects models for joint modeling of sequence data in longitudinal studies. BMC Proceedings. 2014; 8.

25. Schill W. Applied Longitudinal Data Analysis for Epidemiology. Publications of the American Statistical Association. 2004;99:1207-8.

26. Avelar Rodriguez D, Toro Monjaraz EM, Ignorosa Arellano KR, Ramirez Mayans J. Childhood obesity in Mexico: social determinants of health and other risk factors. BMJ case reports. 2018; 2018:r2017223862.

27. Sampasa-Kanyinga H, Colman I, Hamilton HA, Chaput JP. Outdoor physical activity, compliance with the physical activity, screen time, and sleep duration recommendations, and excess weight among adolescents. Obes Sci Pract. 2020;6:196-206.

28. Moraes-Silva IC, Mostarda CT, Silva-Filho AC, Irigoyen MC. Hypertension and Exercise Training: Evidence from Clinical Studies. ADV EXP MED BIOL. 2017;1000:65-84.

\section{Tables}


Table 1

Process assessment of cluster RCT

\begin{tabular}{|c|c|c|c|c|c|c|c|c|c|}
\hline Time point & $\begin{array}{l}\text { Start of } \\
\text { intervention(baseline) } \\
\mathrm{T}_{1}=0 \text { month }\end{array}$ & $\begin{array}{l}\mathrm{T}_{2}=3 \\
\text { months }\end{array}$ & $\begin{array}{l}T_{3}= \\
\text { 6months }\end{array}$ & $\begin{array}{l}T_{4}= \\
\text { 9months }\end{array}$ & $\begin{array}{l}T_{5}= \\
12 \\
\text { month }\end{array}$ & $\begin{array}{l}T_{6}=24 \\
\text { months }\end{array}$ & $\begin{array}{l}T_{7}=36 \\
\text { months }\end{array}$ & $\begin{array}{l}T_{8}=48 \\
\text { months }\end{array}$ & $\begin{array}{l}T_{9}=60 \\
\text { months }\end{array}$ \\
\hline $\begin{array}{l}\text { Intervention } \\
\text { method } 1\end{array}$ & $\sqrt{ }$ & $\sqrt{ }$ & $\sqrt{ }$ & $\sqrt{ }$ & $\sqrt{ }$ & $x$ & $x$ & $x$ & $x$ \\
\hline $\begin{array}{l}\text { Intervention } \\
\text { method } 2\end{array}$ & $\sqrt{ }$ & $\sqrt{ }$ & $\sqrt{ }$ & $\sqrt{ }$ & $\sqrt{ }$ & $x$ & $x$ & $x$ & $x$ \\
\hline $\begin{array}{l}\text { Intervention } \\
\text { method } 3\end{array}$ & $\sqrt{ }$ & $\sqrt{ }$ & $\sqrt{ }$ & $\sqrt{ }$ & $\sqrt{ }$ & $x$ & $x$ & $x$ & $x$ \\
\hline $\begin{array}{l}\text { Intervention } \\
\text { method } 4\end{array}$ & $\sqrt{ }$ & $x$ & $x$ & $x$ & $x$ & $x$ & $x$ & $x$ & $x$ \\
\hline \multicolumn{10}{|l|}{ Investigation } \\
\hline $\begin{array}{l}\text { Learning } \\
\text { related } \\
\text { issues }\end{array}$ & $\sqrt{ }$ & $x$ & $x$ & $x$ & $\sqrt{ }$ & $x$ & $\sqrt{ }$ & $x$ & $\sqrt{ }$ \\
\hline $\begin{array}{l}\text { Work and } \\
\text { rest related } \\
\text { issues }\end{array}$ & $\sqrt{ }$ & $x$ & $x$ & $x$ & $\sqrt{ }$ & $x$ & $\sqrt{ }$ & $x$ & $\sqrt{ }$ \\
\hline $\begin{array}{l}\text { Diet and } \\
\text { exercise } \\
\text { related } \\
\text { issues }\end{array}$ & $\sqrt{ }$ & $x$ & $x$ & $x$ & $\sqrt{ }$ & $x$ & $\sqrt{ }$ & $x$ & $\sqrt{ }$ \\
\hline $\begin{array}{l}\text { Bullying } \\
\text { related } \\
\text { issues }\end{array}$ & $\sqrt{ }$ & $x$ & $x$ & $x$ & $\sqrt{ }$ & $x$ & $\sqrt{ }$ & $x$ & $\sqrt{ }$ \\
\hline $\begin{array}{l}\text { Smoking } \\
\text { and drinking } \\
\text { related } \\
\text { issues }\end{array}$ & $\sqrt{ }$ & $x$ & $x$ & $x$ & $\sqrt{ }$ & $x$ & $\sqrt{ }$ & $x$ & $\sqrt{ }$ \\
\hline $\begin{array}{l}\text { Reading and } \\
\text { writing } \\
\text { postures }\end{array}$ & $\sqrt{ }$ & $x$ & $x$ & $x$ & $\sqrt{ }$ & $x$ & $\sqrt{ }$ & $x$ & $\sqrt{ }$ \\
\hline $\begin{array}{l}\text { Near work } \\
\text { related } \\
\text { issues }\end{array}$ & $\sqrt{ }$ & $x$ & $x$ & $x$ & $\sqrt{ }$ & $x$ & $\sqrt{ }$ & $x$ & $\sqrt{ }$ \\
\hline $\begin{array}{l}\text { Screen time } \\
\text { related } \\
\text { issues }\end{array}$ & $\sqrt{ }$ & $x$ & $x$ & $x$ & $\sqrt{ }$ & $x$ & $\sqrt{ }$ & $x$ & $\sqrt{ }$ \\
\hline \multicolumn{10}{|l|}{$\begin{array}{l}\text { Physical } \\
\text { examination }\end{array}$} \\
\hline Height, m & $\sqrt{ }$ & $\sqrt{ }$ & $\sqrt{ }$ & $\sqrt{ }$ & $\sqrt{ }$ & $\sqrt{ }$ & $\sqrt{ }$ & $\sqrt{ }$ & $\sqrt{ }$ \\
\hline Weight, kg & $\sqrt{ }$ & $\sqrt{ }$ & $\sqrt{ }$ & $\sqrt{ }$ & $\sqrt{ }$ & $\sqrt{ }$ & $\sqrt{ }$ & $\sqrt{ }$ & $\sqrt{ }$ \\
\hline $\begin{array}{l}\text { Systolic } \\
\text { pressure, } \\
\mathrm{mmHg}\end{array}$ & $\sqrt{ }$ & $\sqrt{ }$ & $\sqrt{ }$ & $\sqrt{ }$ & $\sqrt{ }$ & $\sqrt{ }$ & $\sqrt{ }$ & $\sqrt{ }$ & $\sqrt{ }$ \\
\hline $\begin{array}{l}\text { diastolic } \\
\text { pressure, } \\
\mathrm{mmHg}\end{array}$ & $\sqrt{ }$ & $\sqrt{ }$ & $\sqrt{ }$ & $\sqrt{ }$ & $\sqrt{ }$ & $\sqrt{ }$ & $\sqrt{ }$ & $\sqrt{ }$ & $\sqrt{ }$ \\
\hline $\begin{array}{l}\text { Axial length } \\
\mathrm{R} / \mathrm{L}, \mathrm{mm}\end{array}$ & $\sqrt{ }$ & $\sqrt{ }$ & $\sqrt{ }$ & $\sqrt{ }$ & $\sqrt{ }$ & $\sqrt{ }$ & $\sqrt{ }$ & $\sqrt{ }$ & $\sqrt{ }$ \\
\hline
\end{tabular}




\begin{tabular}{|c|c|c|c|c|c|c|c|c|c|}
\hline Time point & $\begin{array}{l}\text { Start of } \\
\text { intervention(baseline) } \\
\mathrm{T}_{1}=0 \text { month }\end{array}$ & $\begin{array}{l}\mathrm{T}_{2}=3 \\
\text { months }\end{array}$ & $\begin{array}{l}\mathrm{T}_{3}= \\
6 \text { months }\end{array}$ & $\begin{array}{l}\mathrm{T}_{4}= \\
\text { 9months }\end{array}$ & $\begin{array}{l}T_{5}= \\
12 \\
\text { month }\end{array}$ & $\begin{array}{l}\mathrm{T}_{6}=24 \\
\text { months }\end{array}$ & $\begin{array}{l}\mathrm{T}_{7}=36 \\
\text { months }\end{array}$ & $\begin{array}{l}\mathrm{T}_{8}=48 \\
\text { months }\end{array}$ & $\begin{array}{l}T_{9}=60 \\
\text { months }\end{array}$ \\
\hline visual acuity & $\sqrt{ }$ & $\sqrt{ }$ & $\sqrt{ }$ & $\sqrt{ }$ & $\sqrt{ }$ & $\sqrt{ }$ & $\sqrt{ }$ & $\sqrt{ }$ & $\sqrt{ }$ \\
\hline $\begin{array}{l}\text { spherical } \\
\text { equivalent,D }\end{array}$ & $\sqrt{ }$ & $\sqrt{ }$ & $\sqrt{ }$ & $\sqrt{ }$ & $\sqrt{ }$ & $\sqrt{ }$ & $\sqrt{ }$ & $\sqrt{ }$ & $\sqrt{ }$ \\
\hline \multicolumn{10}{|l|}{$\begin{array}{l}\text { Biological } \\
\text { sampling }\end{array}$} \\
\hline Saliva & $\sqrt{ }$ & $x$ & $x$ & $x$ & $x$ & $x$ & $x$ & $x$ & $x$ \\
\hline Urine & $\sqrt{ }$ & $x$ & $x$ & $x$ & $x$ & $\sqrt{ }$ & $\sqrt{ }$ & $\sqrt{ }$ & $\sqrt{ }$ \\
\hline Faeces & $\sqrt{ }$ & $x$ & $x$ & $x$ & $x$ & $\sqrt{ }$ & $\sqrt{ }$ & $\sqrt{ }$ & $\sqrt{ }$ \\
\hline
\end{tabular}

\section{Figures}

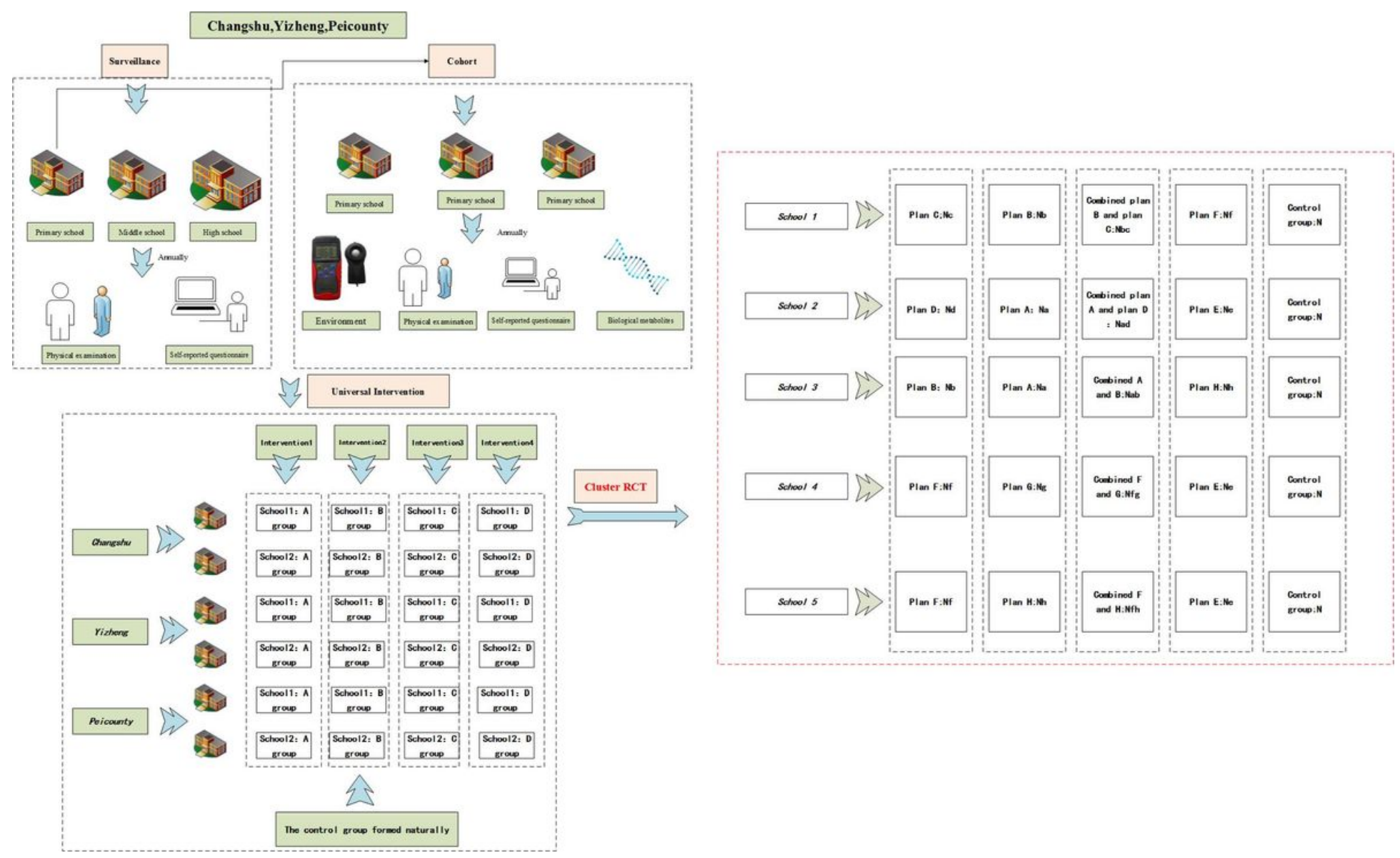

Figure 1

Flow chart of the ES-SCl study

\section{Supplementary Files}

This is a list of supplementary files associated with this preprint. Click to download.

- RCTSPIRITChecklistdownload8Jan13.doc 